(c) American Dairy Science Association, 2004.

\title{
Genetic Selection for Health Traits Using Producer-Recorded Data. I. Incidence Rates, Heritability Estimates, and Sire Breeding Values
}

\author{
N. R. Zwald, ${ }^{1}$ K. A. Weigel, ${ }^{1}$ Y. M. Chang, ${ }^{1}$ R. D. Welper,${ }^{2}$ and J. S. Clay ${ }^{3}$ \\ ${ }^{1}$ University of Wisconsin-Madison, Department of Dairy Science, Madison, 53706 \\ ${ }^{2}$ Alta Genetics, Inc., Watertown, WI 53094 \\ ${ }^{3}$ Dairy Records Management Systems, Raleigh, NC 27695
}

\begin{abstract}
The objective of this study was to determine the feasibility of genetic selection for health traits in dairy cattle using data recorded in on-farm herd management software programs. Data regarding displaced abomasum (DA), ketosis (KET), mastitis (MAST), lameness (LAME), cystic ovaries (CYST), and metritis (MET) were collected between January 1, 2001 and December 31, 2003 in herds using Dairy Comp 305, DHI-Plus, or PCDART herd management software programs. All herds in this study were either participants in the Alta Genetics (Watertown, WI) Advantage progeny testing program or customers of the Dairy Records Management Systems (Raleigh, NC) processing center. Minimum lactation incidence rates were applied to ensure adequate reporting of these disorders within individual herds. After editing, DA, KET, MAST, LAME, CYST, and MET data from 75,252 (313), 52,898 (250), 105,029 (429), 50,611 (212), 65,080 (340), and 97,318 (418) cows (herds) remained for analysis. Average lactation incidence rates were $0.03,0.10,0.20,0.10,0.08$, and 0.21 for DA, KET, MAST, LAME, CYST, and MET (including retained placenta), respectively. Data for each disorder were analyzed separately using a threshold sire model that included a fixed parity effect and random sire and herd-year-season of calving effects; both first lactation and all lactation analyses were carried out. Heritability estimates from first lactation (all lactation) analyses were $0.18(0.15)$ for DA, 0.11 (0.06) for KET, 0.10 (0.09) for MAST, 0.07 (0.06) for LAME, 0.08 (0.05) for CYST, and 0.08 (0.07) for MET. Corresponding heritability estimates for the pooled incidence rate of all diseases between calving and $50 \mathrm{~d}$ postpartum were 0.12 and 0.10 for the first and all lactation analyses, respectively. Mean differences in PTA for probability of disease between the 10 best and 10 worst sires were 0.034 for
\end{abstract}

Received June 9, 2004.

Accepted September 10, 2004.

Corresponding author: Kent Weigel; e-mail: kweigel@wisc.edu.
DA, 0.069 for KET, 0.130 for MAST, 0.054 for LAME, 0.039 for CYST, and 0.120 for MET. Based on the results of this study, it appears that genetic selection against common health disorders using data from onfarm recording systems is possible.

(Key words: health disorders, disease resistance, genetic selection)

Abbreviation key: CYST = cystic ovaries, DA = displaced abomasum, DRMS = Dairy Records Management Systems, KET = ketosis, LAME = lameness, $\mathbf{L I R}=$ lactation incidence rate, $\mathbf{M A S T}=$ mastitis, MET $=$ metritis

\section{INTRODUCTION}

Genetic improvement programs in dairy cattle have traditionally focused on enhancing net profit through increases in gross income per cow, rather than decreases in expenses. However, disorders such as displaced abomasum (DA), ketosis (KET), mastitis (MAST), lameness (LAME), cystic ovaries (CYST), and metritis (MET) can dramatically affect the profitability of dairy herds through involuntary culling, veterinary treatments, added labor, and lost milk sales (Kossaibati and Esslemont, 1997; Shaver, 1997). Guard (1998) estimated that these diseases cost from $\$ 151$ per case for KET to $\$ 312$ per case for DA. Although the phenotypic incidence of one of these diseases can impair subsequent milk production of the affected animal, there is also an antagonistic genetic relationship between most disease traits and milk production (Rauw et al., 1998). Weigel (2003) noted that early metabolic disorders, lameness, and mastitis tend to impair female fertility. Because the majority of selection emphasis during the last $50 \mathrm{yr}$ focused on higher milk production per cow, disease resistance within the global dairy cattle population has been adversely affected (Rauw et al., 1998). Negative energy balance seems to be associated with increased incidence rates for many diseases (Collard et al., 2000). Generally, high-producing dairy cows enter negative energy balance early in lactation, when they 
Table 1. On-farm codes or acronyms used to record the 6 health disorders analyzed in the present study.

\begin{tabular}{|c|c|c|c|c|c|}
\hline $\begin{array}{l}\text { Displaced } \\
\text { abomasum }\end{array}$ & Ketosis & Mastitis & Lameness & $\begin{array}{l}\text { Cystic } \\
\text { ovaries }\end{array}$ & Metritis \\
\hline DA & KETOSIS & MAST & $\mathrm{ABCS}$ & CYST & MET/RP \\
\hline D.A. & KETOTIC & $\mathrm{RF}$ & ABSS & CYSTG & MET \\
\hline LDA & KET & $\mathrm{LF}$ & HROT & CYSTO & METR \\
\hline RDA & KETO & $\mathrm{RR}$ & HFROT & CYSTIC & $\mathrm{RP}$ \\
\hline L-DA & KETOS & LR & LAMINIT & RCYST & RETAINP \\
\hline R-DA & KET1 & MLFQ & LAME & LCYST & RETP \\
\hline DAS & KET2 & MLRQ & WRAP & CYSTRO & INFU \\
\hline DALF & KET3 & MRRQ & LAMI & CYSTLO & INF \\
\hline DART & KETI & MRFQ & LIMP & & MTRI \\
\hline DAR & KETR & MLF & SOREFT & & RETN \\
\hline \multirow{11}{*}{ DAL } & KETS & MLR & ABCSRR & & RPL \\
\hline & KETH & MRR & ABCSLR & & RPIN \\
\hline & KETD & MRF & FOOT & & RPRE \\
\hline & KETP & RFMT & FEET & & UCND \\
\hline & METB $^{1}$ & LFMT & & & RTPL \\
\hline & & LRMT & & & UINF \\
\hline & & RRMT & & & PYOM \\
\hline & & M2TIT & & & UTCN \\
\hline & & MASTALL & & & RE-PLA \\
\hline & & MAST2Q & & & \\
\hline & & MAST3Q & & & \\
\hline
\end{tabular}

${ }^{1}$ Used as an acronym for ketosis in herds with the PCDART software only.

are expending more energy than they can consume. The tendency of a cow to enter an extreme state of negative energy balance may have a genetic component, but individual feed intakes cannot be recorded in a cost-effective manner on commercial farms, so direct selection against negative energy balance is impossible (Collard et al., 2000). In response to concerns about fertility, longevity, and disease susceptibility in Holstein cattle, some producers have also looked to crossbreeding as a potential solution (Weigel and Barlass, 2003). The objective of this study was to examine opportunities for reducing the incidence of several common health disorders in lactating Holstein cattle using data recorded within on-farm herd management software programs.

\section{MATERIALS AND METHODS}

Data regarding health disorders that occurred between January 1, 2001 and December 31, 2003 (with calving between January 1, 2001 and August 31, 2003) were available for 2 groups of herds: Alta Genetics (Watertown, WI) Advantage Progeny Test Program cooperators and Dairy Records Management Systems (DRMS) (Raleigh, NC) customers. Data from the former were copied directly from on-farm computers during monthly visits by Alta Genetics employees in herds that used the Dairy Comp 305 (Valley Ag Software, Tulare, CA), PCDART (DRMS, Raleigh, NC), or DHIPlus (DHI-Provo, Provo, UT) software programs. These cooperator herds were clustered in 3 geographical regions: Northeast (NY, PA, VT, MD, VA), Midwest (MN,
IA, WI, IL, MI, OH, IN), and West (WA, ID, OR, CA, TX). These herds were generally well managed, with nearly exclusive use of AI, heavy usage of young progeny test sire semen, and routine spot-checking of parentage information via DNA testing. Data from farms that used the PCDART software program and elected to provide access to health and breeding events of their cattle were uploaded electronically to DRMS monthly. These herds were located primarily in the Northeast, Southeast, South, Midwest (except WI and MN), and Great Plains.

Although attempts were made by Alta Genetics employees to standardize the recording of health events across farms, many herds developed their own userdefined codes or acronyms for various diseases and disorders. Herds that used the PCDART software tended to use $\leq 4$-character acronyms to define specific disorders, whereas herds that used Dairy Comp 305 or DHIPlus used $\leq 7$-character definitions. Because of this heterogeneity, a list of "plausible" codes was compiled for each of the following 6 health disorders: DA, KET, MAST, LAME, CYST, and MET (including retained placenta). These lists are shown in Table 1. Generally only cases considered "clinical" by the producer were recorded. Each lactation record for each cow was considered as either "diseased" or "healthy" for a particular disorder, even if multiple diagnoses or treatments were reported for the same disease. Although certain disorders, such as DA, are likely to occur only once, multiple cases of diseases such as mastitis or lameness can occur within the same lactation. 
Table 2. Summary of the raw and edited health data used in the present study, including lactational incidence rates (LIR) for each disorder.

\begin{tabular}{lcrrrrr}
\hline & $\begin{array}{c}\text { Displaced } \\
\text { abomasum }\end{array}$ & Ketosis & Mastitis & Lameness & $\begin{array}{l}\text { Cystic } \\
\text { ovaries }\end{array}$ & Metritis \\
\hline Total no. of herds & 379 & 527 & 724 & 581 & 831 & 639 \\
Minimum LIR (\%) & 1 & 3 & 5 & 3 & 3 & 3 \\
Maximum LIR (\%) & 15 & 39 & 60 & 50 & 39 & 50 \\
Mean LIR (\%) & 3 & 10 & 20 & 10 & 8 & 21 \\
Useable herds (\%) & 83 & 47 & 59 & 36 & 41 & 65 \\
Useable herds (no.) & 313 & 250 & 429 & 212 & 340 & 418 \\
No. of records & 134,871 & 100,342 & 199,827 & 92,318 & 117,170 & 181,322 \\
No. of cows & 75,252 & 52,898 & 105,029 & 50,611 & 65,080 & 97,316 \\
No. of sires & 2172 & 1205 & 4983 & 1109 & 3071 & 2163 \\
\hline
\end{tabular}

Minimum lactational incidence rates (LIR) were applied for each of the aforementioned disorders to ensure adequate reporting of specific events within individual herds. Minimum LIR (reported cases/yr) were 0.01 for DA, 0.05 for MAST, and 0.03 for KET, LAME, CYST, and MET. Maximum LIR of 0.50 cases/yr were also applied for LAME and MET, because routine preventative treatment of certain groups of animals resulted in extremely high LIR for some herds. Minimum and maximum LIR were applied separately for each trait, such that individual herds were included in the subsequent analyses of $0,1,2,3,4,5$, or all 6 traits. After editing, data consisted of 134,871 lactation records from 75,252 cows in 313 herds for DA; 100,342 records from 52,898 cows in 250 herds for KET; 199,827 records from 105,029 cows in 429 herds for MAST; 92,318 records from 50,611 cows in 212 herds for LAME; 117,170 records from 65,080 cows in 340 herds for CYST, and 181,322 records from 97,318 cows in 418 herds for MET. A detailed summary of data can be found in Table 2 .

Incidence data corresponding to each disorder were analyzed separately with a threshold sire model, which accounted for the binary $(0,1)$ nature of the data. This model postulated the existence of an unobservable, underlying variable $l$, which represented the liability to disease for a particular animal, and a conceptual threshold, $T$, which represented the liability above which disease will be expressed. Because the threshold, $T$, is not identifiable (Harville and Mee, 1984) its value is constrained to zero, and this defines the origin on the liability scale. Hence, the binary response variable for a given animal, $\mathrm{y}_{\mathrm{i}}$, is determined according to the following rule:

$$
\begin{aligned}
& \text { If } l_{\mathrm{i}} \geq 0 \text {, then } \mathrm{y}_{\mathrm{i}}=1 \text { (i.e., the animal is diseased) } \\
& \text { If } l_{\mathrm{i}}<0 \text {, then } \mathrm{y}_{\mathrm{i}}=0 \text { (i.e., the animal is healthy) }
\end{aligned}
$$

The liability to disease for a particular animal, $l_{\mathrm{ijk}}$, was modeled as follows:

$$
l_{\mathrm{ijkl}}=\mu+\mathrm{P}_{\mathrm{i}}+\operatorname{hys}_{\mathrm{j}}+\mathrm{s}_{\mathrm{k}}+\mathrm{e}_{\mathrm{ijkl}}
$$

where $\mu=$ mean liability to disease for an "average" animal, $\mathrm{P}_{\mathrm{i}}=$ fixed effect of parity (primiparous vs. multiparous), hys $_{\mathrm{j}}=$ random effect of herd-year-season of calving (Jan-June, July-Dec), $\mathrm{s}_{\mathrm{k}}=$ random effect of sire, distributed as $\mathrm{N}\left(\mathbf{0}, \mathbf{A} \sigma_{\mathrm{s}}^{2}\right)$, where $\mathbf{A}$ is the numerator relationship matrix between sires, and $\mathrm{e}_{\mathrm{ijkl}}=$ random residual, modeled as $\mathrm{N}(\mathbf{0}, \mathbf{I})$.

Although it would have been theoretically preferable to use an animal model, the existence of extreme category problems (i.e., individual subclasses that contain either all failures or all successes) tends to cause numerical difficulties (Sorenson and Gianola, 2002), especially for traits with low LIR. Likewise, application of a sire-maternal grandsire model would have been challenging, because only $18 \%$ of these cows had maternal grandsires with valid National Association of Animal Breeders (Columbia, MO) identification codes (many of these herds had recently expanded, and DNA testing for parentage verification began only $3 \mathrm{yr}$ ago). Furthermore, inclusion of a permanent environmental effect to account for the correlation between repeated measures on the same animal would have been problematic, because recording and centralization of health data began only recently, and a large proportion of animals had data from a single lactation only. For these reasons, 2 separate analyses were carried out for each trait, one containing all available lactation records, and one consisting of first lactation records only. Although the former included nearly twice as much data, it was susceptible to selection bias among animals with missing first parity records and improper modeling of the covariance structure due to lack of independence between repeated records on the same animal. Therefore, an analysis including only first lactation records and, hence, excluding the parity effect $\left(\mathrm{P}_{\mathrm{i}}\right)$, was also carried out.

\section{RESULTS AND DISCUSSION}

A summary of the data, before and after editing, is shown in Table 2. Average LIR were 0.03, 0.10, 0.20, 
Table 3. Stage of lactation, measured as days in milk, for first incidence of each of the 6 health disorders considered in this study.

\begin{tabular}{llllrrr}
\hline & \multicolumn{5}{c}{ Health trait } \\
\cline { 2 - 6 } $\begin{array}{l}\text { Days in } \\
\text { milk }\end{array}$ & $\begin{array}{l}\text { Displaced } \\
\text { abomasum }\end{array}$ & Ketosis & Mastitis & Lameness & $\begin{array}{l}\text { Cystic } \\
\text { ovaries }\end{array}$ & Metritis \\
\hline 0 to 30 & $78.5 \%$ & $90.3 \%$ & $23.4 \%$ & $12.2 \%$ & $2.8 \%$ & $60.4 \%$ \\
31 to 60 & $8.3 \%$ & $6.3 \%$ & $8.9 \%$ & $7.8 \%$ & $13.0 \%$ & $8.6 \%$ \\
61 to 90 & $1.8 \%$ & $0.9 \%$ & $8.8 \%$ & $7.3 \%$ & $16.5 \%$ & $5.2 \%$ \\
91 to 120 & $1.6 \%$ & $0.4 \%$ & $8.6 \%$ & $6.7 \%$ & $14.9 \%$ & $5.9 \%$ \\
121 to 150 & $1.6 \%$ & $0.4 \%$ & $7.9 \%$ & $8.0 \%$ & $12.3 \%$ & $5.4 \%$ \\
151 to 180 & $1.3 \%$ & $0.3 \%$ & $7.5 \%$ & $10.3 \%$ & $9.6 \%$ & $3.7 \%$ \\
181 to 210 & $1.3 \%$ & $0.3 \%$ & $7.1 \%$ & $7.5 \%$ & $7.4 \%$ & $2.7 \%$ \\
211 to 240 & $1.1 \%$ & $0.2 \%$ & $6.4 \%$ & $7.1 \%$ & $5.7 \%$ & $2.0 \%$ \\
241 to 270 & $1.3 \%$ & $0.1 \%$ & $5.8 \%$ & $7.3 \%$ & $4.4 \%$ & $1.5 \%$ \\
271 to 300 & $1.1 \%$ & $0.2 \%$ & $4.5 \%$ & $6.6 \%$ & $3.3 \%$ & $1.2 \%$ \\
301 to 330 & $0.6 \%$ & $0.1 \%$ & $3.1 \%$ & $5.1 \%$ & $2.6 \%$ & $0.9 \%$ \\
331 to 360 & $0.5 \%$ & $0.1 \%$ & $2.2 \%$ & $3.7 \%$ & $2.1 \%$ & $0.7 \%$ \\
$>360$ & $1.0 \%$ & $0.3 \%$ & $5.8 \%$ & $10.5 \%$ & $5.5 \%$ & $1.8 \%$ \\
\hline
\end{tabular}

0.10, 0.08, and 0.21 for DA, KET, MAST, LAME, CYST, and MET, respectively. Corresponding percentages of usable herds were $83,47,59,36,41$, and $65 \%$, respectively. The higher percentage of usable records for DA, relative to the other traits, likely reflects the objective, unambiguous diagnosis of this trait. For other traits, such as KET or LAME, uniform diagnosis may more be difficult, and the threshold at which an animal receives veterinary treatment may vary between farms, veterinarians, or groups of animals (e.g., with different milk yield, stage of lactation, or pregnancy status). Removal of herds with extremely high LIR for traits such as LAME or MET and, hence, suspicion of routine preventative treatments, also presents several challenges. For example, a particular herd might code all treated animals as LAME, making differentiation between clinical disease and preventative treatment impossible. However, another herd might code clinically diseased animals as "LAMI", "ABCS", or "HROT" and preventative treatments as "FEET", such that exclusion of the herd would be unwarranted, and differentiation between treatment types would be possible. Overall, herds that used Dairy Comp 305 or PCDART were more likely to record diseases and, hence, to pass edits, than herds that used DHI-Plus. However, nearly all DHI-Plus herds were located in CA, ID, or WA, and this difference may simply reflect regional tendencies among producers to fail to record health events.

Table 3 shows the distribution of incidences of each disorder, according to month of lactation. As expected, the majority of cases of KET (90\%), DA (79\%), and MET (61\%) occurred during the first $30 \mathrm{~d}$ of lactation. The other diseases were more evenly distributed throughout the lactation, with slightly more cases of MAST reported early in lactation; cases of CYST are generally only reported during the breeding period.
Heritability estimates for each of the 6 health disorders are in Table 4. Estimates from the first lactation analysis were $0.18 \pm 0.01$ for DA, $0.11 \pm 0.007$ for KET, $0.10 \pm 0.003$ for MAST, $0.07 \pm 0.003$ for LAME, $0.08 \pm$ 0.005 for CYST, and $0.08 \pm 0.004$ for MET. In general, these estimates were slightly larger than estimates from the analysis that included all available lactation records for every animal. This trend may be due to an increase in the number and magnitude of environmental factors affecting older cows (e.g., changes in ration, movements between pens, exposure to pathogens), or it may simply reflect inadequacies in the model (i.e., the aforementioned limitations in accounting for selection bias and modeling the covariance between repeated records on the same animal).

Differences in the probability of disease between sire progeny groups were evident in the frequency distributions of sire PTA, as shown in Figure 1, as were differences in the mean LIR between daughters of sires with the highest and lowest PTA for each disorder, as shown in Table 5.

Among the traits examined in this study, DA had the highest estimated heritability, 0.18 in the first lactation analysis and 0.15 in the all lactation analysis. These estimates were slightly lower than those of Uribe et al. (1995) but slightly higher than estimates by Van Dorp et al. (1998). Although the heritability estimates for DA seem fairly high, given the known role of management and nutrition for this particular disorder, the recording of DA appears to be very complete in most herds, and licensed veterinarians diagnose nearly all cases. Perhaps the high cost of treatment, coupled with the corresponding drop in milk production, lead farmers to record this trait more completely than other disorders examined in this study. Furthermore, DA is truly a binary trait, as there is no ambiguity or subjectivity regarding 
Table 4. Heritability estimates ( \pm SE) from the first lactation and all lactation analyses for each health trait and for pooled incidence of any disease (among these 6 diseases) between calving and $50 \mathrm{~d}$ postpartum.

\begin{tabular}{lll}
\hline Disorder & Analysis & Heritability \\
\hline Displaced abomasum & 1st lactation & $0.18 \pm 0.010$ \\
& All lactations & $0.15 \pm 0.006$ \\
Ketosis & 1st lactation & $0.11 \pm 0.007$ \\
& All lactations & $0.06 \pm 0.005$ \\
Mastitis & 1st lactation & $0.10 \pm 0.003$ \\
& All lactations & $0.09 \pm 0.003$ \\
Lameness & 1st lactation & $0.07 \pm 0.003$ \\
& All lactations & $0.06 \pm 0.003$ \\
Cystic ovaries & 1st lactation & $0.08 \pm 0.005$ \\
Metritis & All lactations & $0.05 \pm 0.005$ \\
& 1st lactation & $0.08 \pm 0.004$ \\
Any disease within 50 d postpartum & All lactations & $0.07 \pm 0.003$ \\
& 1st lactation & $0.12 \pm 0.005$ \\
& All lactations & $0.10 \pm 0.004$ \\
\hline
\end{tabular}

the severity of the disease. The mean PTA for probability of DA was 0.017 for best 10 sires, whose daughters most successfully resisted the disorder, and 0.061 for the worst 10 sires, whose daughters were most susceptible. This indicates that, under equivalent herd management conditions, approximately $1.7 \%$ of daughters of the best sires would have a DA in a given lactation, as compared with about $6.1 \%$ of daughters of the worst sires.

The estimated heritability of KET was nearly twice as large in the first lactation analysis (0.11), as compared with the all lactation analysis (0.06). Estimates from the present study were consistent with those of Uribe et al. (1995) but were lower than those reported by Van Dorp et al. (1998).

A possible explanation for the higher heritability of KET among first-parity cows may be that these animals have not yet had a dry period. An abnormally short or long dry period may lead to improper nutrition in the weeks before calving, and this additional environmental factor may increase the residual variance or decrease the genetic variance. Although KET is often a precursor to DA, the heritability of the former is much lower. This difference is most likely due to the subjective diagnosis of KET, compared with DA, which leads to inconsistent recording between herds and between employees within a herd. The range in sire PTA for probability of disease was from 0.063 to 0.132 for the sires transmitting most resistance and most susceptibility to KET, respectively. Sires that transmit resistance to KET or DA may simply be producing daughters that have greater appetites pre- and postcalving, such that these cows can avoid extreme negative energy balance (Collard et al., 2000).

Because MAST occurs throughout lactation, the single incidence model used herein may not be as accurate as the multiple-trait longitudinal binary models used by Heringstad et al. (2003) and Chang et al. (accepted).
In the present study, MAST had an estimated heritability of 0.10 in the first lactation analysis and 0.09 in the multiple lactation analysis. These estimates are slightly lower than the early lactation estimate of 0.16 reported by Chang et al. (accepted), but they are similar to full-lactation heritability estimates reported by $\mathrm{He}-$ ringstad et al. (2003) and Uribe et al. (1995), and higher than the 0.04 estimate of Van Dorp et al. (1998). These estimates are also similar to the heritability value (0.10) for routine genetic evaluation of SCS in the United States (www.aipl.arsusda.gov). These findings suggest that an economic index including both SCS and clinical MAST would increase the effectiveness of genetic selection for mastitis resistance, as recommended by Nash et al. (2000). Average sire PTA for probability of MAST ranged from 0.129 to 0.259 for sires that transmitted the most resistance and most susceptibility to MAST, respectively. It is interesting to note that the sire with the highest probability for mastitis in our study (0.259) also had the highest PTA for SCS (3.91) among sires in our data set.

The presence or absence of CYST during routine veterinary examinations had a heritability estimate of 0.07 in the first lactation analysis and 0.05 in the all lactation analysis. This estimate was lower than that of Uribe et al. (1995), but higher than estimates obtained by Van Dorp et al. (1998) and Hooijer et al. (2000). Furthermore, these estimates were slightly higher than heritabilities reported recently for other reproductive traits, such as daughter pregnancy rate (VanRaden, 2003). Roth et al. (1999) noted that the incidence rate of CYST has increased over time, and this has had an unfavorable effect on the reproductive performance of today's dairy cow population. Although the range in PTA for CYST was relatively small (0.052 to 0.091), this result shows that the incidence of CYST could be reduced though selection. However incidence of CYST is not necessarily a good measure of female reproductive 

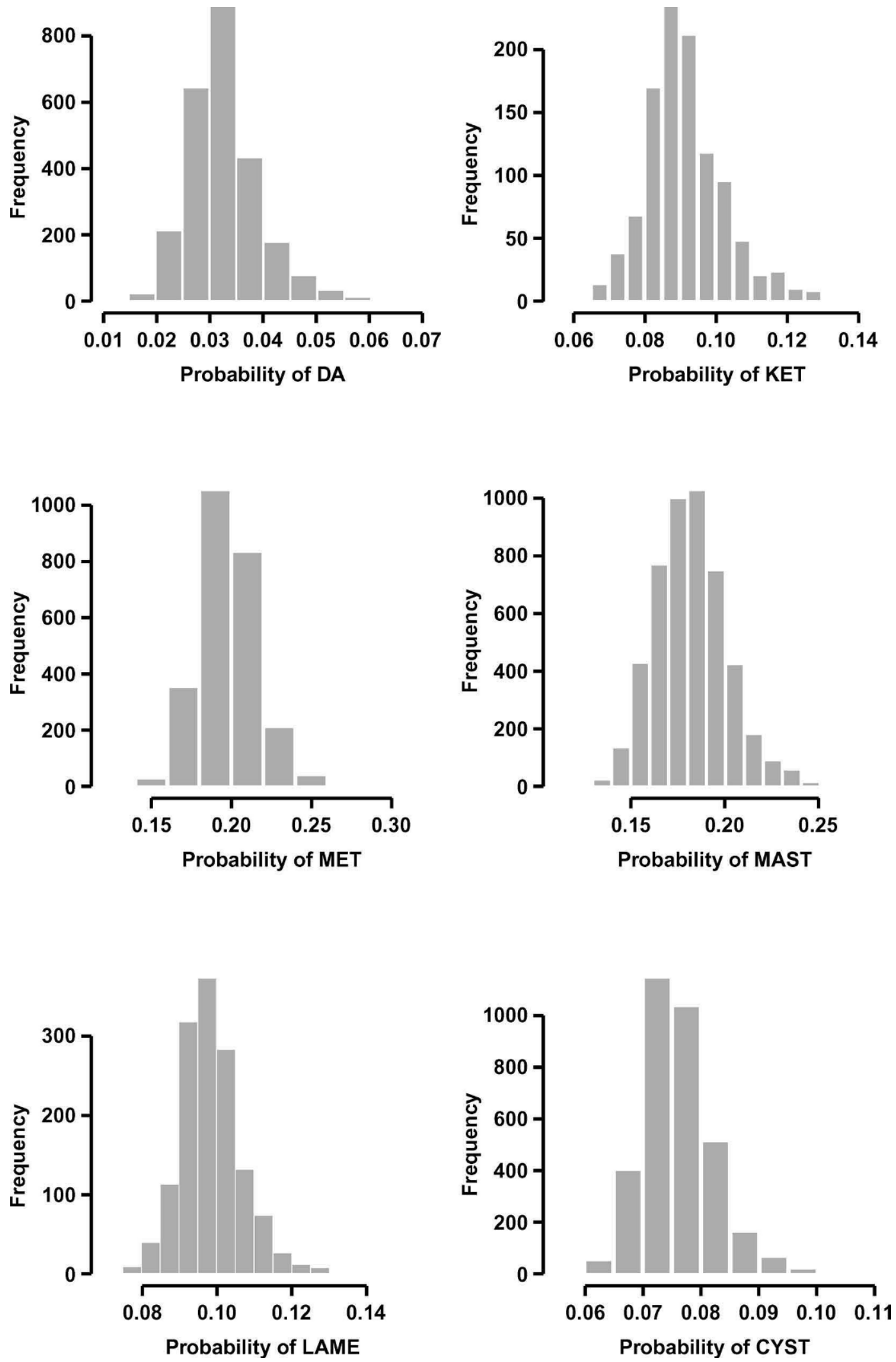

Figure 1. Distribution of sire PTA, expressed as probabilities of disease, for displaced abomasum (DA), ketosis (KET), metritis (MET), mastitis (MAST), lameness (LAME), and cystic ovaries (CYST). 
Table 5. Sires' PTA for daughters' probability of disease, as well as daughters' actual lactational incidence rates (LIR) for each of the 6 health disorders considered in this study.

\begin{tabular}{|c|c|c|c|c|c|c|}
\hline & $\begin{array}{l}\text { Displaced } \\
\text { abomasum }\end{array}$ & Ketosis & Mastitis & Lameness & $\begin{array}{l}\text { Cystic } \\
\text { ovaries }\end{array}$ & Metritis \\
\hline Mean PTA for probability of disease (all sires) & 0.033 & 0.099 & 0.182 & 0.099 & 0.076 & 0.198 \\
\hline SD of PTA for probability of disease (all sires) & 0.007 & 0.009 & 0.019 & 0.008 & 0.006 & 0.018 \\
\hline Mean PTA for probability of disease (worst 10 sires) & 0.061 & 0.132 & 0.259 & 0.131 & 0.091 & 0.271 \\
\hline Mean of daughters' actual LIR (best 10 sires) & 0.010 & 0.066 & 0.087 & 0.051 & 0.032 & 0.241 \\
\hline Mean of daughters' actual LIR (worst 10 sires) & 0.051 & 0.122 & 0.346 & 0.091 & 0.067 & 0.435 \\
\hline
\end{tabular}

performance, because some anovular cows continue to cycle, whereas other cows without the cysts are anovular.

The estimated heritability of LAME was similar in the first lactation (0.06) and all lactation (0.07) analyses. However, these values are only about half as large as heritability estimates for feet and leg conformation traits in Holsteins, which generally fall within the range of 0.10 to 0.15 . Heritability estimates for LAME from the present study were lower than those reported by Uribe et al. (1995), Van Dorp et al. (1998), and Boettcher et al. (1998), who obtained estimates of 0.15, 0.16 , and 0.22 , respectively.

Heritability estimates for MET were also similar in the first lactation (0.08) and all lactation (0.07) analyses. These estimates were higher than the estimates of 0.04 for MET and 0.02 for retained placenta reported by Van Dorp et al. (1998). The LIR for MET in most herds were relatively high, and clear definition of this disorder was difficult due to the wide range in recording methods between farms. Initially, the acronym "INFUSE" was considered as a metritis event; however, some herds routinely infuse a large proportion of the animals, regardless of their clinical infection status, and the LIR of these herds often exceeded 0.80 . Therefore, we applied a maximum LIR of 0.50 for each herd included in the analysis, and this constraint led to more reasonable estimates of the sire variance. Also, many herds use the "MET/RP" acronym for recording both MET and retained placenta. In our analysis, we grouped these disorders together as uterine problems, but perhaps these different traits should be recorded and analyzed separately.

An alternative to analyzing each of the 6 health disorders separately and then incorporating them into a selection index is to pool all diseases into a single analysis. In this study, we considered a composite trait in which all diseases that occurred within the first $50 \mathrm{~d}$ postpartum were considered as a single trait, regardless of which specific disease actually occurred. Because CYST is not typically diagnosed within the first $50 \mathrm{~d}$ postpartum, this disease was excluded from the pooled analysis. Estimated heritabilities of disease incidence within the first $50 \mathrm{~d}$ of lactation were 0.12 in the first lactation analysis and 0.10 in the all lactation analysis; these were higher than estimates for most of the individual disease traits. Sire PTA for probability of disease within the first $50 \mathrm{~d}$ postpartum ranged from 0.13 to 0.37 . This appears to indicate that positive genetic or phenotypic relationships exist between these early lactation diseases. Information about the incidence of disease within the first $50 \mathrm{~d}$ postpartum might be a more timely trait than information about specific diseases over the course of the entire lactation. Furthermore, analysis of disease incidence by $50 \mathrm{~d}$ postpartum may be less computationally demanding than a multiple-trait analysis that considers several specific diseases, and fewer genetic covariance parameters would be needed.

\section{CONCLUSIONS}

This study showed that significant genetic differences exist between dairy sires in their daughters' susceptibility to common health disorders when clinical cases of these diseases are recorded by farmers within their herd management software programs. Heritability estimates for the 6 disease traits examined in this study ranged from 0.05 to 0.18 , and analyses that included only first lactation records tended to provide slightly higher estimates than analyses that included all available lactation records. The difference between first lactation and all lactation analyses may have been due to selection bias, as only cows that were relatively healthy in first lactation would have had an opportunity to be recorded in subsequent lactation. Among the 6 diseases studied herein, DA had the largest genetic component, most likely because the diagnosis of this disorder is relatively objective, and recording practices are therefore somewhat standard within and between herds. In this study, animals recorded as receiving treatment for a certain disease were, in fact, considered to have had that disease. This approach can be a challenge; however, for disorders such as ketosis and metritis, in which cows are sometimes treated as a preventative measure.

Heritabilities of individual disease traits were sufficient to incorporate these traits, with appropriate eco- 
nomic weights, into a selection index. However, LIR for some traits were relatively low, and it may be interesting to consider composite measures of disease, such as the presence or absence of disease within the first 50 d postpartum. In this study, the pooled incidence of DA, KET, MAST, LAME, and MET before $50 \mathrm{~d}$ postpartum had higher estimated heritability than most of the individual disease traits. Most diseases and metabolic disorders tend to occur around calving time or shortly thereafter. Furthermore, many of these diseases are phenotypically related to each other (e.g., a cow with KET is more likely to experience a DA). Therefore, overall disease resistance in the first $50 \mathrm{~d}$ of lactation may be an interesting, timely trait to include in genetic selection programs.

Overall, the low incidence rates and binary recording practices for most disease traits, coupled with small progeny group sizes for many North American dairy sires, are key challenges with respect to establishing accurate, effective selection programs for these traits. However, significant progress can be made if breeding companies are willing to concentrate their progeny testing in herds that routinely record the incidence of health disorders and increase the average number of progeny test daughters per sire. At present, there is no standard program for recording, centralizing, storing, or analyzing information about disease traits in US dairy cattle. Nonetheless, a wealth of information is currently being recorded in on-farm computer systems, and the vast majority of this information is being left on the farm, rather than used. Future work should focus on standardizing trait definitions and diagnoses, implementing systems for routine data transfer and storage, and developing tools to verify the accuracy and completeness of the resulting information.

\section{ACKNOWLEDGMENTS}

The authors gratefully acknowledge financial support for this project by Alta Genetics (Watertown, WI), and the USDA-ARS Animal Improvement Programs Laboratory (Beltsville, MD).

\section{REFERENCES}

Boettcher, P. J., J. C. M. Dekkers, L. D. Warnick, and S. J. Wells. 1998. Genetic analysis of clinical lameness in dairy cattle. J. Dairy Sci. 81:1148-1156.
Chang, Y. M., D. Gianola, B. Heringstad, and G. Klemetsdal. Effects of trait definition on genetic parameter estimation in sire evaluation for clinical mastitis with threshold models. Anim. Sci. (accepted).

Collard, B. L., P. J. Boettcher, J. C. M. Dekkers, D. Petitclerc, and L. R. Schaeffer. 2000. Relationships between energy balance and health traits of dairy cattle in early lactation. J. Dairy Sci. 83:2683-2690.

Guard, C. 1998. Fresh cow problems are costly: Culling hurts the most. Proc. Ann. Conf. Vet. Med., Cornell Univ., Ithaca, NY.

Harville, D. A., and R. W. Mee. 1984. A mixed-model procedure for analyzing ordered categorical data. Biometrics 40:393-408.

Heringstad, B., Y. M. Chang, D. Gianola, and G. Klemetsdal. 2003. Genetic analysis of longitudinal trajectory of clinical mastitis in first-lactation Norwegian cattle. J. Dairy Sci. 86:2676-2683.

Hooijer, G. A., R. B. F. Lubbers, B. J. Ducro, J. A. M. van Arendonk, L. M. T. E. Kaal-Lansbergen, and T. van der Lende. 2000. Genetic parameters for cystic ovarian disease in Dutch Black and White dairy cattle. J. Dairy Sci. 84:286-291.

Kossaibati, M. A., and R. J. Esslemont. 1997. The costs of production diseases in dairy herds in England. Vet. J. 154:41-51.

Nash, D. L., G. W. Rogers, J. B. Cooper, G. L. Hargrove, J. F. Keown, and L. B. Hansen. 2000. Heritability of clinical mastitis incidence and relationships with sire transmitting abilities for somatic cell score, udder type traits, productive life, and protein yield. J. Dairy Sci. 83:2350-2360.

Rauw, W. M., E. Kanis, E. N. Noordhuizen-Stassen, and F. J. Grommers. 1998. Undesirable side effects of selection for high production efficiency in farm animals: A review. Livest. Prod. Sci. 56:15-33.

Roth, A., E. Strandberg, P. Berland, U. Emanuelson, and J. Philipsson. 1999. Genetic correlations among female fertility traits and milk production in different parities in Swedish dairy cattle. Pages 177-181 in Occasional Publ. No. 24, British Society of Animal Science, Penicuik, UK.

Shaver, R. D. 1997. Nutritional risk factors in the etiology of left displaced abomasum in dairy cows: A review. J. Dairy Sci. 80:2249-2253.

Sorenson, D., and D. Gianola. 2002. Likelihood, Bayesian and MCMC Methods in Quantitative Genetics. Springer-Verlag. New York, NY

Uribe, H. A., B. W. Kennedy, S. W. Martin, and D. F. Kelton. 1995. Genetic parameter estimates for common health disorders of Holstein cows. J. Dairy Sci. 78:421-430.

Van Dorp, T. E., J. C. M. Dekkers, S. W. Martin, and J. P. T. M. Noordhuizen. 1998. Genetic parameters of health disorders, and relationships with 305-day milk yield and conformation traits of registered Holstein cows. J. Dairy Sci. 81:2264-2270.

VanRaden, P. M. 2003. Genetic evaluations for fitness and fertility in the United States and other nations. Pages 103-106 in Proc. Natl. Dairy Genetics Workshop, Raleigh, North Carolina. FASS, Savoy, IL.

Weigel, K. A. 2003. Improving the reproductive efficiency of dairy cattle through genetic selection. J. Dairy Sci. 87(E. Suppl.):E86-E92.

Weigel, K. A., and K. Barlass. 2003. Results of a producer survey regarding crossbreeding on US dairy farms. J. Dairy Sci. 86:4148-4154. 